\title{
Simvastatin and biphasic calcium phosphate affects bone formation in critical-sized rat calvarial defects ${ }^{1}$
}

\author{
Washington Macedo de Santana ${ }^{\mathrm{I}}$, Dircilei Nascimento de Sousa ${ }^{\mathrm{I}}$, Vania Maria Ferreira ${ }^{\mathrm{II}}$, Wagner Rodrigues Duarte ${ }^{\mathrm{II}}$ \\ DOI: http://dx.doi.org/10.1590/S0102-865020160050000002 \\ IFellow PhD degree, Postgraduate Program in Health Sciences, School of Health Sciences, Campus Universitário Darcy Ribeiro, Universidade de \\ Brasilia (UnB), Brasília-DF, Brazil. Technical procedures, acquisition and interpretation of data, manuscript writing. \\ IIPhD, Full Professor, School of Health Sciences, Department of Pharmaceutical Sciences, Campus Universitário Darcy Ribeiro, UnB, Brasília-DF, \\ Brazil. Statistical analysis, English language, critical revision. \\ IIIPhD, Associate Professor, School of Health Sciences, Department of Dentistry, Campus Universitário Darcy Ribeiro, UnB, Brasília-DF, Brazil. \\ Conception and design of the study, manuscript writing.
}

\begin{abstract}
PURPOSE: To investigate the effects of locally applied simvastatin plus biphasic calcium phosphate (BoneCeramic $\left.{ }^{\circledR}\right)$ or collagen sponge on bone formation in critical-sized bone defects.

METHODS: Thirty defects of $5 \mathrm{~mm}$ in diameter were created bilaterally with a trephine bur in the calvariae of fifteen Wistar rats. The defects were divided into five groups: group 1 - control, no treatment; group 2 (BoneCeramic ${ }^{\circledR}$ ); group 3 (BoneCeramic ${ }^{\circledR}+0.1 \mathrm{mg}$ simvastatin); group 4 (collagen sponge); and group 5 (collagen sponge $+0.1 \mathrm{mg}$ simvastatin). After eight weeks the animals were euthanized and their calvariae were histologically processed. Hematoxylin and eosin-stained sections were subjected to histological and histomorphometrical analyses. The area of newly formed bone was calculated and compared between groups.

RESULTS: The greater amount of a bone-like tissue was formed around the carrier in group 3 (BoneCeramic ${ }^{\circledR}+0.1 \mathrm{mg}$ simvastatin) followed by group 2 (BoneCeramic ${ }^{\circledR}$ ), and almost no bone was formed in the other groups. Group 3 was significantly different compared to group 2, and both groups were significantly different compared to the other groups.
\end{abstract}

CONCLUSION: Simvastatin combined with BoneCeramic ${ }^{\circledR}$ induced significantly greater amounts of newly formed bone and has great potential for the healing of bone defects.

Key words: Simvastatin. Osteogenesis. Calcium Phosphates. Rats. 


\section{Introduction}

Important structural changes on bone such as reduction on bone height and width occur as a consequence of periodontal disease and tooth extraction. Such bone changes may compromise the functional and esthetic oral rehabilitation of the patients and require bone grafting procedures ${ }^{1,2}$. Autogenous bone is an osteogenic, osteoinductive and osteoconductive material that has been considered the gold standard material for bone graft. It is totally biocompatible and rich on factors essential for osteoblast differentiation such as bone morphogenetic proteins (BMPs), especially BMP-2 which is a potent bone inductive growth factor, and vascular endothelial growth factor (VEGF) which has angiogenic property ${ }^{3,4}$. On the other hand, autogenous bone grafts have a few disadvantages such as its resorption potential and the need for a donor area as a second surgical site which may be limited in certain clinical situations ${ }^{5}$.

Calcium phosphate ceramic materials have been commonly used as autogenous bone substitutes due to their excellent biocompatibility. These ceramic materials have also been used as carriers for drugs and growth factors such as BMPs $^{6,7}$. Among the several calcium phosphate materials reported in the literature, Straumann BoneCeramic ${ }^{\circledR}$, a biphasic calcium phosphate (BCP), is a totally synthetic material composed of $60 \%$ hidroxyapatite (HA) and $40 \% \beta$-tricalcium phosphate $(\beta \text {-TCP })^{8}$. A clinical advantage of this chemical composition is that, while resorption of the $\beta$-TCP component occurs at a faster rate allowing early bone formation, the HA component is slowly resorbed, thus providing a long-term space maintenance for the late formation of new bone within a bone defect ${ }^{8}$. Furthermore, BoneCeramic ${ }^{\circledR}$ has been shown to be safe, biocompatible, and an effective scaffold for new bone formation in several types of bone defects on the alveolar ridge and maxillary sinus $s^{9,10}$. Despite its positive results in terms of new bone formation, BoneCeramic ${ }^{\circledR}$ is an osteoconductive material that lacks osteoinductive properties. Several recent reports have pointed out to the fact that the use of biologically active molecules with osteoinductive activity could be associated with scaffolds used in bone defects, resulting in osteoconductive and osteoinductive bone substitute materials ${ }^{12}$.

Statins are drugs that have been widely used to lower blood cholesterol levels in the past several years. However, many studies have investigated the systemic and local effects of statins on bone metabolism and healing of bone defects ${ }^{13,14}$. When locally applied, statins affect bone healing through osteoinduction by increasing angiogenesis and modulating proteins and growth factors $^{15,16}$. Simvastatin, one of the statins, has been locally applied in different concentrations with different carriers to induce bone formation in bone defects, but the ideal combination of drug concentration/type of carrier is still uncertain ${ }^{17}$. Nevertheless, lower concentrations of simvastatin $(0.1 \mathrm{mg})$ have been shown to be better when ceramic carries are utilized ${ }^{18}$.

In the present study we hypothesized that he combination of BoneCeramic ${ }^{\circledR}$ and simvastatin would result in improved bone formation in the widely used critical-sized rat calvarial bone defect mode $^{19}$ when compared with BoneCeramic ${ }^{\circledR}$ alone. Furthermore, in order to verify whether simvastatin could overcome the lack of osteoconductive or osteoinductive activities in a carrier, the combination of simvastatin with a collagen sponge was also tested.

\section{Methods}

The study protocol was approved by the Committee for the Use of Animals on Research, Universidade de Brasilia, (protocol UnB doc 44299-2012).

Fifteen female Wistar rats (eight weeks of age, average weight of $300 \mathrm{~g}$ ) were used in this study. The animals were housed in groups of five per cage, kept under standard conditions with food and water ad libitum, room temperature, light/dark cycle of 12 hours (06:00 to 18:00 h).

\section{Preparation of simvastatin solution}

The simvastatin solution was prepared and applied to the bone defects as previously described ${ }^{19}$. Briefly, a solution containing $0.1 \mathrm{mg}$ of simvastatin diluted in $15 \mu \mathrm{l}$ ethanol (Farmogral, Brasília-DF, Brazil) was applied to each bone defect created on rat calvaria as described below. Two different carriers were used for the simvastatin: Straumann BoneCeramic ${ }^{\circledR}(400-700$ $\mu \mathrm{m}$ ) (Institut Straumann AG, Basel, Switzerland) or a collagen sponge (CollaTape ${ }^{\circledR}$, Zimmer Dental, Carlsbad, CA, USA). The bone defects treated with simvastatin and BoneCeramic ${ }^{\circledR}$ received $14 \mathrm{mg}$ of the carrier soaked in $15 \mu \mathrm{l}$ of simvastatin solution. The defects treated with CollaTape and simvastatin, received a round piece of the collagen sponge of the size of the defect soaked in $15 \mu \mathrm{l}$ of simvastatin solution.

\section{Surgical procedures}

The animals were anesthetized with a combination of ketamine $(80 \mathrm{mg} / \mathrm{kg})$ and xylazine $(10 \mathrm{mg} / \mathrm{kg})$ by an intramuscular injection. An antiseptic (povidone-iodine) was applied to the surgical sites, a skin incision was performed, and a flap was raised 
exposing the calvarial bone. Two critical-sized bone defects of $5 \mathrm{~mm}$ in diameter just lateral to the sagittal plane were carefully prepared with a trephine bur (Neodent, Curitiba-PR, Brazil) under irrigation with saline solution and slight pressure to avoid damage to the the dura mater of the brain. A total of 30 defects were created on fifteen 15 rats and divided in 5 groups that included 6 defects for each group treated as follows: group 1, control group (C) - no treatment; group 2, BoneCeramic ${ }^{\mathbb{B}}(\mathrm{BC})$; group 3, BoneCeramic ${ }^{\mathbb{R}}$ + Simvastatin (BCS); group 4, collagen sponge - CollaTape ${ }^{\circledR}$

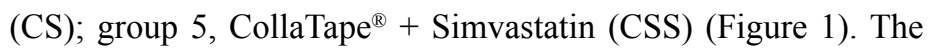
flaps were then sutured with a 5-0 nylon suture (Ethicon ${ }^{\circledR}$, São Paulo-SP, Brazil). Aspirin (150mg/kg) was given orally to the rats every 6 hours on the first day after surgery. The animals were observed daily for signs of inflammation. For the histological and histomorphometrical analyses, the animals were euthanized by decapitation eight weeks after surgery.
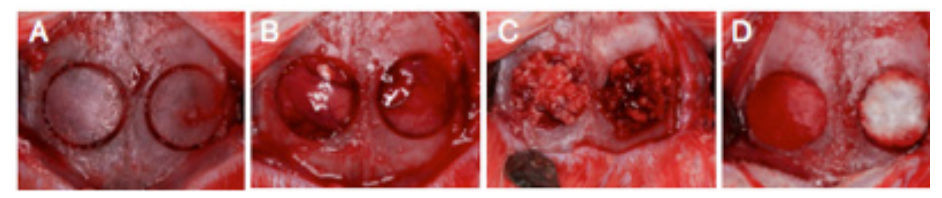

FIGURE 1 - Representative photographs of the surgical procedures. (A) Osteotomies created with a trephine on the parietal bone. (B) Bone defects exbited after removal of cortical bone. (C) Bone defects treated

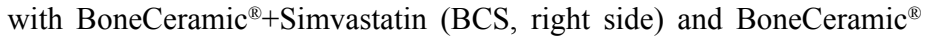
(BC, left side). (D) Bone defects treated with CollaTape ${ }^{\circledR}+$ Simvastatin (CSS, right side) and CollaTape ${ }^{\circledR}$ (CS, left side).

\section{Histological preparation}

After euthanize, the calvarial bones were dissected out, the soft tissues were carefully removed, and the specimens were then fixed in neutral $10 \%$ formalin for 24 hours. The specimens were then washed in water for 24 hours and decalcified with a solution of $50 \%$ formic acid and $20 \%$ sodium citrate for 30 days. The calvarial bones were longitudinally divided in half and each half containing one treated defect was embedded separately in paraffin according to standard protocols. The embedded specimens were sectioned into $5 \mu \mathrm{m}$ serial slices with a microtome. All sections were stained with hematoxylin and eosin for later microscopic and histomorphometrical analyses.

\section{Histological and histomorphometrical analyses}

Histological analysis was carried out with a light microscope (Zeiss, Jena, Germany) under x20 and x200 magnification and the morphology of the newly formed tissue in the bone defect area was examined. Tissue sections were screened under a light microscope and the most central histological sections of each surgical defect was selected for the analyses.

The histomorphometrical analysis was carried out with the ImageScope ${ }^{\circledR}$ software (Leica Biosystems, São Paulo-SP, Brazil) and the area of the newly formed bone was calculated according to a previously described method ${ }^{20}$. Briefly, the total area was delineated on the captured digital images of the entire surgical defects as follows: two vertical lines were drawn on each side of the defect that was limited by the original cortical calvarial bone. These two vertical lines on each side were connected by two horizontal lines, one on top and another at the bottom, forming a rectangle containing the entire newly formed tissue within the confines of this rectangle. The area of this rectangle was considered to be $100 \%$ of the area to be analyzed (total area). Then, only the newly formed bone was selected and its area calculated as a percentage of the total area.

\section{Statistical analysis}

For the statistical analysis, the area of the newly formed bone in the groups was evaluated by a commercial software (SAS 9.3) with One-way analysis of variance (ANOVA), and a significant difference between groups of $\mathrm{p}<0.05$ was established. The data were further analyzed by Tukey method for post hoc multiple comparisons test.

\section{Results}

\section{Histological analysis}

Figure 2 shows an overview of the entire healed defect of all groups at low magnification (x20) with the panels arranged from the thinnest to the thickest newly formed tissue. In group 1 (control), there was no evidence of new bone formation (Figure $2 \mathrm{~A})$. In group 2, which was treated with only BoneCeramic ${ }^{\circledR}(\mathrm{BC})$, a newly formed tissue suggestive of bone was observed with a more intense staining similar to the original bone tissue at the border of the defect (Figure 2D). The newly formed tissue observed in group 3 (BCS), that was treated with BC soaked with simvastatin, was more evident as compared to the other groups (Figure 2E). In group 3, the entire length of the defect was filled by a tissue with a width similar to that of the border of the defect. In both groups 2 and 3, spaces left by BC particles were present (Figures 2D and E, asterisks). In group 4, the defect was treated only with a collagen sponge (CS) and a fibrous tissue layer apparently thicker that that of the control group was observed, whereas in group 5, that was 
treated with a collagen sponge soaked in simvastatin (CSS), the presence of a fibrous tissue thicker than the one observed in groups 1 and 4 (control and CS, respectively) was present (Figures 2B and C).
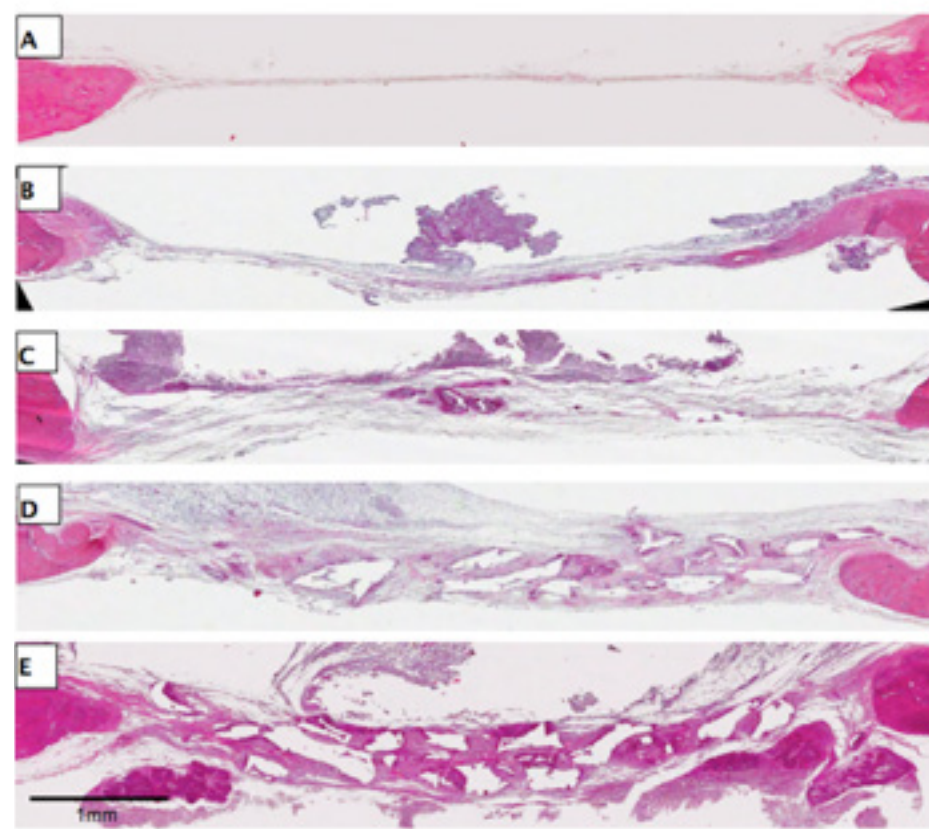

FIGURE 2 - Representative photomicrographs showing an overview of the entire healed defect of all groups, arranged according to their increased thickness. (A) Group 1: control group, no treatment. (B) Group 4: CollaTape ${ }^{\circledR}$. (C) Group 5: CollaTape ${ }^{\circledR}+$ Simvastatin. (D) Group 2: BoneCeramic ${ }^{\mathbb{}}$. (D) Group 3: BoneCeramic ${ }^{\mathbb{Q}}+$ Simvastatin (original magnification $\mathrm{x} 20$ ).

In a higher magnification (x200), only a thin fibrous tissue was present in the defect area in the control group (Figure 3).

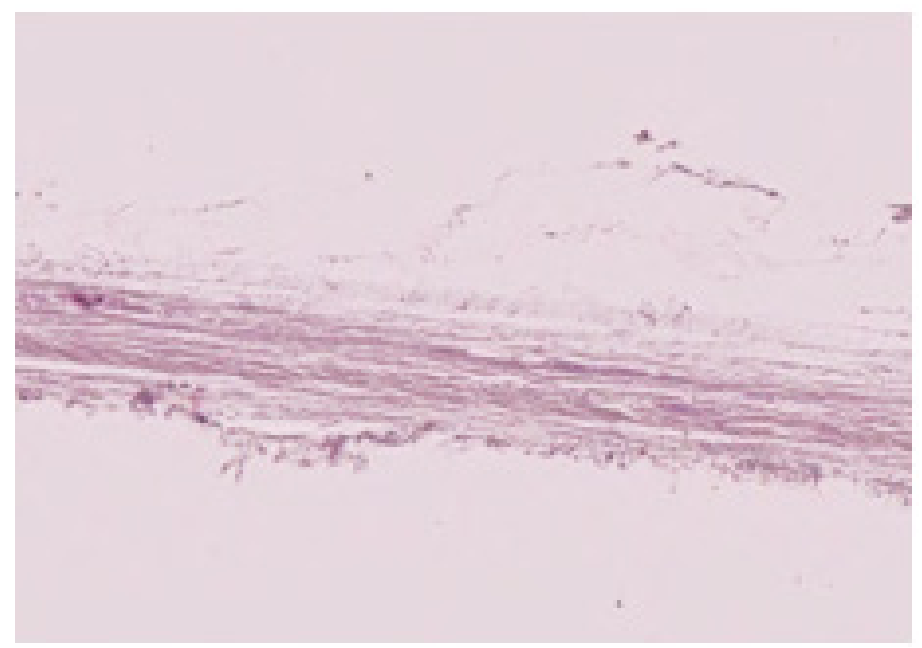

FIGURE 3 - Representative photomicrograph of group 1 (control, no treatment) at a magnification of $\times 200$ depicting a thin fibrous tissue formed in the wounded area.
In group 2, several cuboidal cells located at the surface of the BC particles (spaces left by the BC particles after demineralization, (Figure 4, asterisks) with morphological characteristics of osteoblasts were observed (Figure 4, arrows). These cells were surrounded by a bone-like matrix and in some areas, several osteoblast-like cell layers were present. The location of the cells on the surface of the $\mathrm{BC}$, the bone-like matrix surrounding the cells, and their morphological appearance indicates that those cells are osteoblasts in bone matrix synthetic activity. Around the $\mathrm{BC}$ particles we also observed a connective tissue rich in fibroblastic cells and blood vessels (Figure 4).

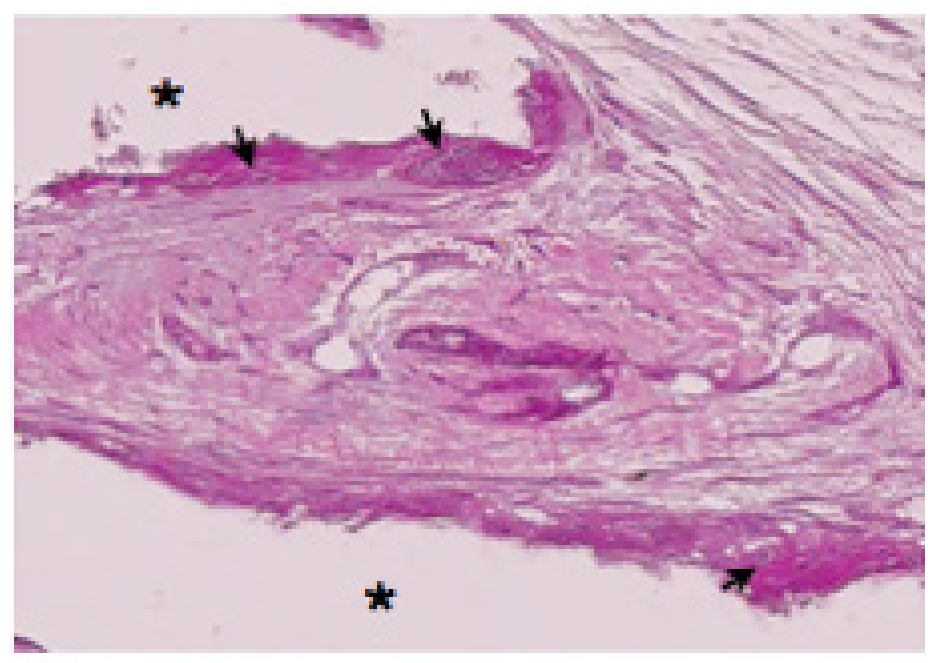

FIGURE 4 - Representative photomicrograph of group 2 (BC, BoneCeramic $\left.^{\mathbb{B}}\right)$ at a magnification of $\mathrm{x} 200$ showing several cuboidal cells with morphological characteristics of osteoblasts (arrows) located at the surface of the $\mathrm{BC}$ particles (spaces left by the BC particles after demineralization, asterisks).

In group 3 a newly formed bone-like tissue was observed in close proximity to the BC particles (spaces left by the particles after demineralization, (Figure 5, asterisks). This was also observed in group 2, however, in group 3 the staining of the tissue was more intense and the amount of the bone-like tissue in group 3 was visually greater that that of group 2 (Figure 5). When compared to group 2, a greater number of cuboidal cells aligned on the surface of the BC particles was observed in group 3, and in many regions, several layers of osteoblastic cells were present (Figure 5, arrows). Thick layers of a bone-like matrix around the osteoblastic cells were present, suggesting a great activity of bone matrix synthesis. A connective tissue surrounding the $\mathrm{BC}$ particles with many fibroblastic cells and blood vessels was also observed (Figure 5). 


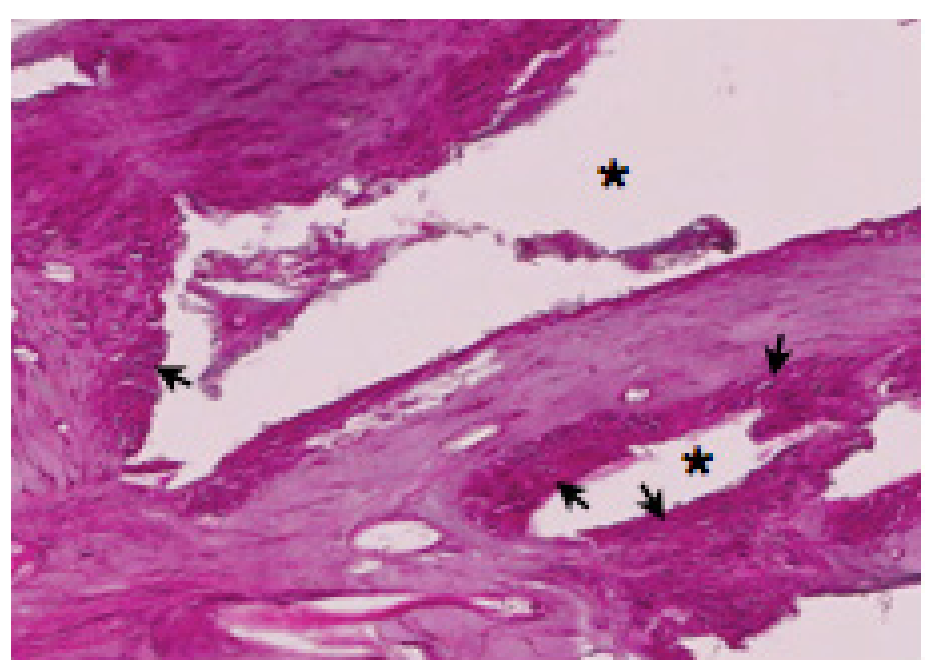

FIGURE 5 - Representative photomicrograph of group 3 (BCS, BoneCeramic $^{\mathbb{Q}}+$ Simvastatin) at a magnification of $\times 200$ showing a great number of cuboidal cells with morphological characteristics of osteoblasts aligned on the surface of the $\mathrm{BC}$ particles (spaces left by the $\mathrm{BC}$ particles after demineralization, asterisks) and thick layers of a bone-like matrix around the osteoblastic cells (arrows).

In group 4, in the region close to the center of the defect, the presence of a tissue with a more intense staining and a different characteristic than the fibrous tissue was observed. Remnants of the collagen sponge were not present and a few cells and blood vessels were observed (Figure 6). In group 5, in the center of the defect, a small island of a bone-like tissue was observed with the presence of cuboidal cells aligned on the surface, which is characteristic of osteoblasts surrounded by a bone-like matrix (Figure 7, arrows).

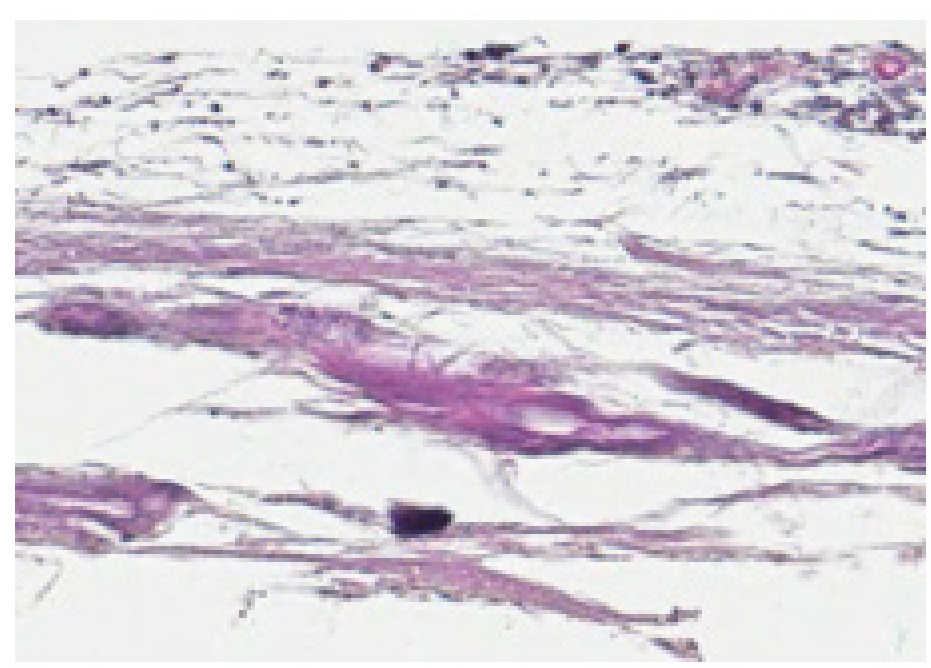

FIGURE 6 - Representative photomicrograph of group 4 (CollaTape ${ }^{\sqrt{8}}$ ) at a magnification of $\mathrm{x} 200$ showing a fibrous tissue and no evidence of bone formation.

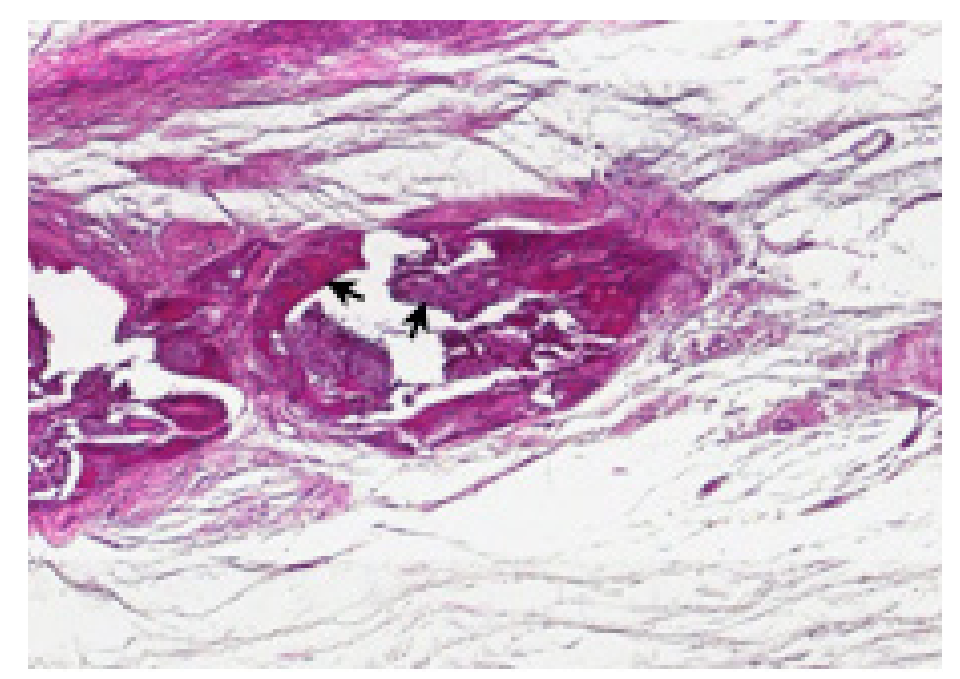

FIGURE 7 - Representative photomicrograph of group 5 (CollaTape $^{\circledR}+$ Simvastatin) at a magnification of $\times 200$ depicitng a small island of a bone-like tissue with cuboidal cells aligned on the surface (arrows).

\section{Histomorphometrical analysis}

The mean values for the area of newly formed bone tissue (ANB) was higher in group 3 (BCS) as compared to all the other groups. The mean values of the ANB in groups 3 (BCS), 2 (BC), and 5 (CSS) were significantly higher than that of group 1 (control group). The mean value of the ANB in group 3 (BCS) was significantly higher than that of group 2 (BC). The mean value of ANB of group 4 (CS) was not significantly different from that of group 1 (control group). Similarly, the mean value of ANB of group 5 (CSS) was not significantly different from that of group 4 (CS) (Table 1).

TABLE 1 - Comparison of new bone formation among all groups.

\begin{tabular}{cccc}
\hline Groups & $\%$ ANB \pm SD & P-value & P-value \\
\hline $1(\mathrm{C})(\mathrm{n}=6)$ & $0.00 \pm 0.00$ & & \\
$2(\mathrm{BC})^{\mathrm{a}, \mathrm{b}}(\mathrm{n}=6)$ & $9.04 \pm 0.86$ & $<0.0001^{\mathrm{a}}$ & \\
$3(\mathrm{BCS})^{\mathrm{a}, \mathrm{b}}(\mathrm{n}=6)$ & $12.71 \pm 1.21$ & $<0.0001^{\mathrm{a}}$ & $<0.001^{\mathrm{b}}$ \\
$4(\mathrm{CS})^{\mathrm{a}, \mathrm{c}}(\mathrm{n}=6)$ & $0.91 \pm 0.86$ & $0.4188^{\mathrm{a}}$ & \\
$5(\mathrm{CSS})^{\mathrm{a}, \mathrm{c}}(\mathrm{n}=6)$ & $2.25 \pm 0.61$ & $0.0024^{\mathrm{a}}$ & $0.1062^{\mathrm{c}}$ \\
\hline
\end{tabular}

$\mathrm{ANB}$, area of new bone; C, control; $\mathrm{BC}$, BoneCeramic ${ }^{\circledR}$; $\mathrm{BCS}$, BoneCeramic $^{\circledR}+$ Simvastatin; CS, CollaTape $^{\circledR}$; CSS, CollaTape ${ }^{\circledR}+$ Simvastatin; SD, standard deviation.

${ }^{a}$ Comparison of all groups with the control group, significant difference at $P<0.05$. All groups significantly different from control.

${ }^{\mathrm{b}}$ Comparison between groups 2 (BC) and 3 (BCS), significant difference at $P<0.05$. Group 3 significantly different from group 2 .

${ }^{\circ}$ Comparison between groups 4 (CS) and 5 (CSS), significant difference at $P<0.05$. Groups 5 not significantly different from group 4 .

Plus-minus values are means $\pm \mathrm{SD}$.

Analysis performed by one-way analysis of variance (ANOVA) and by Tukey method for post hoc multiple comparisons test. 


\section{Discussion}

The results of studies describing the application of simvastatin for the formation of bone in different bone defects have been encouraging and its effects on bone metabolism may have a great potential in medicine and dentistry ${ }^{13,17,21}$. In the present study, simvastatin was applied with two distinct carriers in criticalsized calvarial defects and its impact on new bone formation was evaluated. Similar to several previous reports, the results of the present study show that the use of this drug in fact results in greater new bone formation when applied to the bone defects created in rat calvariae. Taken together, our results and those published by others suggest that simvastatin may have a great potential to improve the results of bone reconstructive procedures. Mundy et al. $1999^{16}$ were the first to report that simvastatin stimulated bone formation. More recently, other in vitro and in vivo studies have described the positive effects of simvastatin in bone tissue, especially when applied locally ${ }^{22,23}$. According to those studies, simvastatin can be locally applied at higher concentrations without side effects, and thus reach an ideal concentration at the local site. Therefore, in the present study, simvastatin was also applied locally with a ceramic carrier $\left(\right.$ BoneCeramic $^{\circledR}$ ) and its bone-inducing capabilities were evaluated.

Several animal studies have focused on determining the ideal concentration of simvastatin for the induction of bone formation. Stein et al. ${ }^{24}$ demonstrated that $0.1 \mathrm{mg}$ of simvastatin in methylcellulose gel in a polylactic acid membrane resulted in minimal local inflammation, but this concentration/carrier did not stimulate significant bone growth. On the other hand, other studies verified that $0.1 \mathrm{mg}$ of simvastatin associated with a ceramic carriers induced the greater bone formation with little inflammation ${ }^{17,25,26}$. Thus, $0.1 \mathrm{mg}$ could be considered the ideal concentration for simvastatin to be locally applied with a ceramic carrier. Therefore, in our study we applied this concentration of simvastatin and, similar to other studies, a greater induction of bone formation was observed. On the other hand, studies have also reported that higher local doses of simvastatin $(2.2 \mathrm{mg})$ result in significant inflammation of the skin over the defects without additional gain on the amount of the newly formed bone, whereas very low doses $(0.01 \mathrm{mg})$ are not capable to stimulate bone formation ${ }^{26}$. In the present study we also verified clinically the presence of a slight inflammatory response on the skin over the surgical site in the groups treated with simvastatin (BCS and CSS), which disappeared after approximately 10 days. This result is consistent with that of other studies, that reported a similar inflammatory response that was resolved after about
10 days of healing ${ }^{17,26}$. Therefore, the inflammation observed in the present study was considered of little importance because it did not negatively affect bone formation, on the contrary, the defects treated with $0.1 \mathrm{mg}$ of simvastatin exhibited greater bone formation, especially when combined with the biphasic calcium phosphate carrier (BoneCeramic ${ }^{\circledR}$ ).

BoneCeramic $^{\circledR} \quad(B C)$ is widely used as a bone substitute grafting material and its osteoconductive properties are well established ${ }^{8-10}$. However, the collagen sponge (CS) is not considered an ideal bone grafting material since it is not osteoconductive, it is quickly resorbed (about one week), and it is not capable of maintaining the space necessary for new bone formation ${ }^{27}$. This was evident on the histological analysis of the present study in which CS was incapable to induce or conduct new bone formation or even induce the formation of a tissue with a similar width as the borders of the defect. Despite that, CS was used as a carrier for simvastatin to verify if the presence of the drug could overcome the deficiencies of the CS. According to our results, a slow resorbing and space keeping material is ideal as a carrier for simvastatin, and the CS lacked those properties. Thus, since BC has those properties, it proved to be an ideal carrier for simvastatin. As pointed out, $\mathrm{BC}$ is an osteoconductive material that lacks osteoinductive properties. The combination of $\mathrm{BC}$ and simvastatin may have resulted in an osteocondutive and osteoinductive material, capable of being at the same time a scaffold and inducing greater new bone formation.

Mukozawa et $a .^{23}$ observed significant new bone formation after eight weeks of healing when a collagen sponge soaked in $2.5 \mathrm{mg}$ of simvastatin solution was placed in $5 \mathrm{~mm}$ bone defects on the nasal bone of rabbits. These results suggested that collagen sponge could be a good carrier for simvastatin. In the present study, the collagen sponge used resulted in minimal new bone formation, which differed from the results shown by Mukozawa et al. ${ }^{23}$ This difference can be attributed to several methodological differences between the studies, since Mukozawa et al. treated the defects with $2.5 \mathrm{mg}$ of simvastatin dissolved in water as opposed to $0.1 \mathrm{mg}$ dissolved in ethanol. Furthermore, although the collagen sponges used in our study and that used by Mukozawa et al. are both of bovine origin, their composition differs. While CollaTape ${ }^{\circledR}$ is composed of type I collagen from bovine tendom, the collagen sponge used by Mukozawa et al. was composed of $85 \%$ to $95 \%$ type I collagen and $5 \%$ to $15 \%$ of type III collagen. Moreover, their results showed that this collagen sponge alone had the capacity to induce some bone formation, which is not the case of CollaTape ${ }^{\circledR 28}$. Therefore, all the differences mentioned above may explain the conflicting results found by us and by Mukozawa et l. $^{23}$ 
Simvastatin is a hydrophobic drug, and therefore it is not soluble in water. Similar to other studies, we used ethanol to dissolve the simvastatin powder. According to Morris et al. ${ }^{29}$, dissolving simvastatin in ethanol facilitates its application in small spaces/defects when compared to a methylcellulose gel containing simvastatin. On the contrary, Tanigo et al. ${ }^{30}$, argue that the incorporation of simvastatin into a biodegradable gelatin of hydrogel favors its release with lesser or no inflammation. In fact, the simvastatin solution used in the present study facilitated the combination with BoneCeramic ${ }^{\circledR}$, which was easily soaked by the solution. The osteoconductive properties of BC was demonstrated in the present study by the results of groups 2 and 3 , whose defects exhibited a greater bone formation and were totally filled with a newly formed tissue of a similar width as the borders of the wound as compared to the groups in which BC was not applied. The combination of simvastatin and BoneCeramic ${ }^{\circledR}$ improved even further the properties of $\mathrm{BC}$, and we hypothesize that the addition of $0.1 \mathrm{mg}$ of simvastatin to $\mathrm{BC}$ resulted in an osseoconductive and osseoinductive grafting material. Thus, this combination may be useful as an alternative grafting material to autogenous bone and may have a great potential to be applied in various bone defects in a clinical setting. Further studies are necessary to test this combination in other types of bone defects.

\section{Conclusion}

BoneCeramic $^{\circledR}$ is a suitable carrier for simvastatin and that their combination induced significantly greater amounts of newly formed bone as compared with BoneCeramic ${ }^{\circledR}$ alone or a collagen sponge carrier.

\section{References}

1. Covani U, Bortolaia C, Barone A, Sbordone L. Bucco-lingual crestal bone changes after immediate and delayed implant placement. J Periodontol. 2004 Dec;75(12):1605-12. PMID: 15732861.

2. Araújo MG, Lindhe J. Dimensional ridge alterations following tooth extraction. An experimental study in the dog. J Clin Periodontol. 2005 Feb;32(2):212-8. PMID: 15691354.

3. Khan SN, Cammisa FP Jr, Sandhu HS, Diwan AD, Girardi FP, Lane JM. The biology of bone grafting. J Am Acad Orthop Surg. 2005 Jan-Feb;13(1):77-86. PMID: 15712985.

4. Miron RJ, Gruber R, Hedbom E, Saulacic N, Zhang Y, Sculean A, Bosshardt DD, Buser D. Impact of bone harvesting techniques on cell viability and the release of growth factors of autografts. Clin Implant Dent Relat. Res 2013 Aug;15(4):481-9. PMID: 22375920.

5. Nkenke E, Neukam FW. Autogenous bone harvesting and grafting in advanced jaw resorption: morbidity, resorption and implant survival. Eur J Oral Implantol. 2014 Summer;7 Suppl 2:S203-17. PMID: 24977256.
6. Verron E, Khairoun I, Guicheux J, Bouler JM. Calcium phosphate biomaterials as bone drug delivery systems: a review. Drug Discov Today. 2010 Jul;15(13-14):547-52. PMID: 20546919.

7. Saito A, Suzuki Y, Kitamura M, Ogata S, Yoshihara Y, Masuda S, Ohtsuki C, Tanihara M. Repair of 20-mm long rabbit radial bone defects using BMP-derived peptide combined with an $\alpha$-tricalcium phosphate scaffold. J Biomed Mater Res A. 2006 Jun;77(4):700-6. PMID: 16550532.

8. Jensen SS, Yeo A, Dard M, Hunziker E, Schenk R, Buser D. Evaluation of a novel biphasic calcium phosphate in standardized bone defects: A histological and histomorphometric study in the mandibles of minipigs. Clin Oral Implants Res. 2007 Dec;18(6):75260. PMID: 17888014.

9. van Assche N, Michels S, Naert I, Quirynen M. Randomized controlled trial to compare two bone substitutes in the treatment of bony dehiscences. Clin Implant Dent Relat Res. 2013 Aug;15(4):558-68. PMID: 22236044.

10. Cordaro L, Bosshardt DD, Palattella P, Rao W, Sereno G, Chiapasco M. Maxillary sinus grafting with Bio-Oss or Straumann BoneCeramic: histomorphometric results from a randomized controlled multicenter clinical trial. Clin Oral Implants Res. 2008 Aug;19(8):796-03. PMID: 18705811.

11. Romagnoli C, D'Asta F, Brandi ML. Drug delivery using composite scaffolds in the context of bone tissue engineering. Clin Cases Miner Bone Metab. 2013 Sep;10(3):155-61. PMID: 24554923.

12. Kolk A, Handschel J, Drescher W, Rothamel D, Kloss F, Belssmann M, Heiland M, Wolff KD, Smeets R. Current trends and future perspectives of bone substitute materials - From space holders to innovative biomaterials. J Cranio-Maxillofacial Surg. 2012 Dec;40(8):706-18. PMID: 22297272.

13. Ayukawa Y, Yasukawa E, Moriyama Y, Ogino Y, Wada H, Atsuta I, Koyano K. Local application of statin promotes bone repair through the suppression of osteoclasts and the enhancement of osteoblasts at bone-healing sites in rats. Oral Surg Oral Med Oral Pathol Oral Radiol Endod. 2009 Mar;107(3):336-42. PMID: 18801677.

14. Ho ML, Chen YH, Liao HJ, Chen CH, Hung SH, Lee MJ, Fu YC, Wang YH, Wang GJ, Chang JK. Simvastatin increases osteoblasts and osteogenic proteins in ovariectomized rats. Eur J Clin Invest. 2009 Apr;39(4):296-03. PMID: 19292885.

15. Zhang Y, Zhang R, Li Y, He G, Zhang D, Zhang F. Simvastatin augments the efficacy of therapeutic angiogenesis induced by bone marrow-derived mesenchymal stem cells in a murine model of hindlimb ischemia. Mol Biol Rep. 2012 Jan;39(1):285-93. PMID: 21553056.

16. Mundy G, Garrett R, Harris S, Chan J, Chen D, Rossini G, Boyce B, Zhao M, Gutierrez G 1. Stimulation of bone formation in vitro and in rodents by statins. Science. 1999 Dec;286(5446):1946-9. PMID: 10583956.

17. Rojbani H, Nyan M, Ohya K, Kasugai S. Evaluation of the osteoconductivity of $\alpha$-tricalcium phosphate, $\beta$-tricalcium phosphate, and hydroxyapatite combined with or without simvastatin in rat calvarial defect. J Biomed Mater Res A. 2011 Sep;98(4):488-98. PMID: 21681941.

18. Sousa DN, Santana WM, Ferreira VM, Duarte WR. Behavioural and cognitive effects of simvastatin dose used in stimulation of bone regeneration in rats. Acta Cir. Bras. 2014 Mar;29(3):151-7. PMID: 24626726 .

19. Stavropoulos A, Sculean A, Bosshardt DD, Buser D, Klinge B. Pre-clinical in vivo models for the screening of bone biomaterials for oral/craniofacial indications: focus on small-animal models. Periodontol 2000. 2015 Jun;68(1):55-65. PMID: 25867979.

20. Melo LGN, Nagata MJH, Bosco AF, Ribeiro LLG, Leite CM. Bone healing in surgically created defects treated with either bioactive 
glass particles, a calcium sulfate barrier, or a combination of both materials. A histological and histometric study in rat tibias. Clin Oral Implants Res. 2005 Dec;16(6):683-91. PMID: 16307575.

21. Rosselli JE, Martins DM, Martins JL, Oliveira CR, Fagundes DJ, Taha MO. The effect of simvastatin on the regeneration of surgical cavities in the femurs of rabbits. Acta Cir. Bras. 2014 Feb;29(2):8792. PMID: 24604311

22. Seto H, Ohba H, Tokunaga K, Hama H, Horibe M, Nagata T. Topical administration of simvastatin recovers alveolar bone loss in rats. J Periodontal Res. 2008 Jun;43(3):261-7. PMID: 18447852.

23. Mukozawa A, Ueki K, Marukawa K, Okabe K, Moroi A, Nakagawa $\mathrm{K}$. Bone healing of critical-sized nasal defects in rabbits by statins in two different carriers. Clin Oral Implants Res. 2011 Nov;22(11):1327-35. PMID: 21732983.

24. Stein, D, Lee Y, Schmid MJ, Killpack B, Genrich MA, Narayana N, Marx DB, Cullen DM, Reinhardt RA. Local simvastatin effects on mandibular bone growth and inflammation. J Periodontol. 2005 Nov;76(11):1861-70. PMID: 16274305.

25. Nyan M, Miyahara T, Noritake K, Hao J, Rodriguez R, Kuroda $\mathrm{S}$, Kasugai S. Molecular and tissue responses in the healing of rat calvarial defects after local application of simvastatin combined with alpha tricalcium phosphate. J Biomed Mater Res B Appl Biomater. 2010 Apr;93(1):65-73. PMID: 20024970.

26. Nyan M, Sato D, Kihara H, Machida T, Ohya K, Kasugai S. Effects of the combination with alpha-tricalcium phosphate and simvastatin on bone regeneration. Clin Oral Implants Res. 2009 Mar;20(3):2807. PMID: 19397639.

27. al-Khateeb TL, Marouf HA, Anwar MM. Modified bovine type I collagen membrane as a wound graft material in oral surgery (an experimental study). J Ir Dent Assoc.1996;42(3):46-50. PMID: 9242117.

28. Ahn JJ, Cho SA, Byrne G, Kim JH, Shin HI. New bone formation following sinus membrane elevation without bone grafting: histologic findings in humans. Int J Oral Maxillofac Implants. 2011 Jan-Feb;26(1):83-90. PMID: 21365042.
29. Morris MS, Lee Y, Lavin MT, Giannini PJ, Schmid MJ, Marx DB, Reinhardt RA. Injectable simvastatin in periodontal defects and alveolar ridges: pilot studies. J Periodontol. 2008 Aug;79(8):146573. PMID: 18672997.

30. Tanigo T, Takaoka R, Tabata Y. Sustained release of waterinsoluble simvastatin from biodegradable hydrogel augments bone regeneration. J Control Release. 2010 Apr;143(2):201-6. PMID: 20060429.

\section{Correspondence:}

Wagner Rodrigues Duarte

Faculdade de Ciências da Saúde, Departamento de Odontologia

Campus Universitário Darcy Ribeiro, UnB

70910-900 Brasília - DF Brasil

Tel.: (55 61)8175-3063

duartew@yahoo.com

Received: Jan 14, 2016

Review: Mar 10, 2016

Accepted: Apr 11, 2016

Conflict of interest: none

Financial source: none

${ }^{1}$ Research performed at Laboratory of Pathology, School of Medicine, Universidade de Brasília (UNB), Brasilia-DF, Brazil. Part of PhD degree thesis, Postgraduate Program in Health Sciences, School of Health Sciences, UnB. Tutor: Dr. Wagner Rodrigues Duarte. 